\title{
Severe Metabolic Acidosis and Pulmonary Edema: A Near-Drowning Case
}

\author{
๑ Yasemin Çoban, @ Mehmet Davutoğlu \\ Kahramanmaraş Sütçü Imam University Faculty of Medicine, Department of Pediatrics, Division of Pediatric Intensive Care Unit, Kahramanmaraş, Turkey
}

\begin{abstract}
Drowning is defined as a situation which results in the death of the patient within the first 24 hours, while "near-drowning" refers to all conditions of submersion which does not cause death but brings about morbidity and damaging effects. A twenty-five-month-old boy was found immobile in a bathtub filled with water. The patient was transported to the intensive care unit from the emergency department where he vas ventilated with a bag-mask, then intubated, and diagnosed with respiratory insufficiency, and his respiration was supported by mechanical ventilator. Physical examination of the patient showed that he was hypothermic, not breathing spontaneously, his heart rate was 120/min., blood pressure 100/80 mmHg, he was unconscious, and Glasgow Coma scale was 5 . The first blood analysis results were mmol/L. The pulmonary edema regressed, cardiopulmonary hemodynamic returned to normal. Then, at the $48^{\text {th }}$ hour he was weaned from mechanical ventilator support. The patient was discharged from the hospital in good health, without negative cognitive and motor symptoms on the $10^{\text {th }}$ day. The present case report aimed to highlight the importance of basic and advanced life support in cases of near-drowning which happens frequently among children, and to discuss the management of pulmonary edema and other complications.

Keywords: Near-drowning, child, pulmonary edema
\end{abstract}

\section{Introduction}

Drowning is defined as a condition resulting in death due to complete submersion or immersion in water. Neardrowning is used to describe all submersions in water not ending in death in the first 24 hours but with accompanying morbidity, and which may give rise to adverse outcomes. Drownings are particularly common in children under 5 and in young adults $(1,2)$. Asphyxia is responsible for morbidity resulting from near-drowning. The effect on the brain depends on the duration, intensity and timing of hypoxia. Hypoxia lasting for 4-10 minutes causes irreversible damage in the hippocampus, basal ganglia and cortex, while hypoxia lasting a few minutes longer results in persistent coma (3). This report discusses therapeutic methods and complications in the light of the existing literature, in a 25-month-old case of near-drowning presenting with severe metabolic acidosis, severe hypoxemia and pulmonary edema.

\section{Case Report}

A 25-month-old boy was found by his family immobile in a trough full of water. It was unclear how long he had been submerged. The patient was ventilated with a balloon mask by the first aid team and brought to our pediatric emergency department. At initial examination, his body temperature was $<36{ }^{\circ} \mathrm{C}$, heart rate 120 beat/min, blood pressure 100/80 mmHg, and Glasgow Coma score (GCS) was 5. The pupils were isocoric, bilateral light reflex $(+)$, and deep tendon reflex was normoactive. His respiration was superficial. The patient was intubated and admitted to the pediatric intensive care unit. He was placed on 
mechanical ventilator support at peak inspiratory pressure 15, positive-end expiratory pressure (PEEP) 5, pressure support ventilation (PSV) 7, $\mathrm{FiO}_{2} 100 \%$, and respiration rate $25 / \mathrm{min}$ in synchronized intermittent mandatory (SIMV)+PS. Arterial blood gas analysis revealed $\mathrm{pH} 6.9, \mathrm{PaCO}_{2} 38.1 \mathrm{mmHg}$, $\mathrm{PaO}_{2} 54 \mathrm{mmHg}, \mathrm{HCO}_{3}: 8 \mathrm{mmol} / \mathrm{L}$, and baz excess (BE) -1.7 $\mathrm{mmol} / \mathrm{L}$. Sodium bicarbonate deficit therapy and $0.45 \%$ $\mathrm{NaCl}+5 \%$ dextrose fluid were started. At follow-up after 1 hour, arterial blood gas was $\mathrm{pH} 7.20, \mathrm{PaCO}_{2} 40 \mathrm{mmHg}, \mathrm{PaO}_{2}$ $75 \mathrm{mmHg}, \mathrm{HCO}_{3} 17 \mathrm{mmol} / \mathrm{L}$, and $\mathrm{BE}-8.8 \mathrm{mmol} / \mathrm{L}$. At the $8^{\text {th }}$ hour, $\mathrm{pH}$ was 7.49, $\mathrm{PaCO}_{2} 16.5 \mathrm{mmHg}, \mathrm{PaO}_{2} 137 \mathrm{mmHg}$, $\mathrm{HCO}_{3} 17 \mathrm{mmol} / \mathrm{L}, \mathrm{BE}-10.4 \mathrm{mmol} / \mathrm{L}$, and lactate $30 \mathrm{mg} / \mathrm{dL}$. Blood gases improved gradually and returned to normal limits in 8 hours. The blood count showed $\mathrm{Hb} 12.4 \mathrm{~g} / \mathrm{dL}$, hematocrit $37.4 \%$, leukocytes $27.610 \mathrm{~mm}^{3}$, and platelets $58.5000 \mathrm{~mm}^{3}$. According to biochemical examinations, sodium was 132 $\mathrm{meq} / \mathrm{L}$, potassium $2.6 \mathrm{meq} / \mathrm{L}$, glucose $132 \mathrm{mg} / \mathrm{dL}$, alkaline phosphatase $29 \mathrm{U} / \mathrm{L}$, aspartate aminotransferase $51 \mathrm{U} / \mathrm{L}$, urea $20 \mathrm{mg} / \mathrm{dL}$, creatinine $0.47 \mathrm{mg} / \mathrm{dL}$, calcium $9.41 \mathrm{mg} /$ $\mathrm{dL}$, and Pediatric Risk of Mortality III score was 22. No findings of hemolysis were observed in peripheral blood smear. Coagulation tests revealed prothrombin time as 14.3 sec., activated partial thromboplastin time $135 \mathrm{sec}$., and international normalized ratio as 1.23. Fresh frozen plasma replacement was administered, and the coagulation tests gave normal results following the replacement. A loading dose of phenytoin of $20 \mathrm{mg} / \mathrm{kg}$ was given due to convulsion during admission, with maintenance of phenobarbital $5 \mathrm{mg} / \mathrm{kg}$. Sedation/analgesia was induced with fentanyl and midazolam infusion. Bilateral, diffuse, homogeneous pulmonary edema was observed at posteroanterior chest X-ray (Figure 1). Control X-ray after 12 hours on invasive mechanical ventilation support showed that expansion had begun in the lungs, and that bilateral homogeneous infiltrations had decreased but still persisted (Figure 2). Clinical and laboratory follow-ups were performed close to the invasive monitor, and the patient was removed from the invasive mechanical ventilator after 48 hours. Cranial computerized tomography performed to exclude cerebral edema was reported as normal.

Suprasternal and intercostal retractions occurred following extubation, and the patient was started on inhaled adrenaline, cold vapor and systematic dexamethasone. The respiratory problems had resolved entirely by the seventh day of hospitalization, no neurological deficit remained, and the patient was removed from intensive care. Cognitive functions were at normal levels for his age at one-month follow-up post-discharge. Written consent was obtained from the patient's parents.

\section{Discussion}

Neurological injury occurring as a result of hypoxemia and ischemia is the primary cause of mortality and morbidity in cases of drowning and near-drowning. Aspiration of

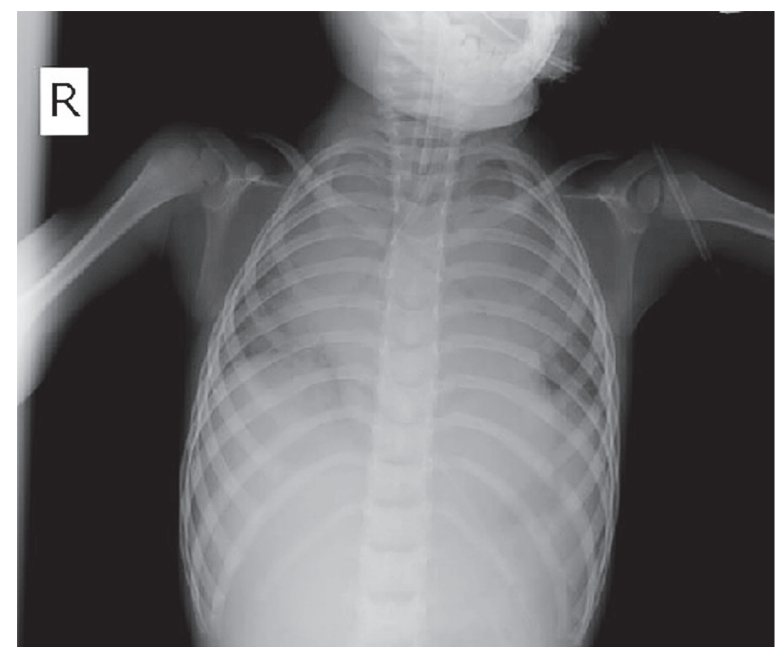

Figure 1. Diffuse, homogeneous pulmonary edema in both lungs in which the heart contours cannot be clearly distinguished. (Appearance $1 \mathrm{~h}$ after the near-drowning incident)

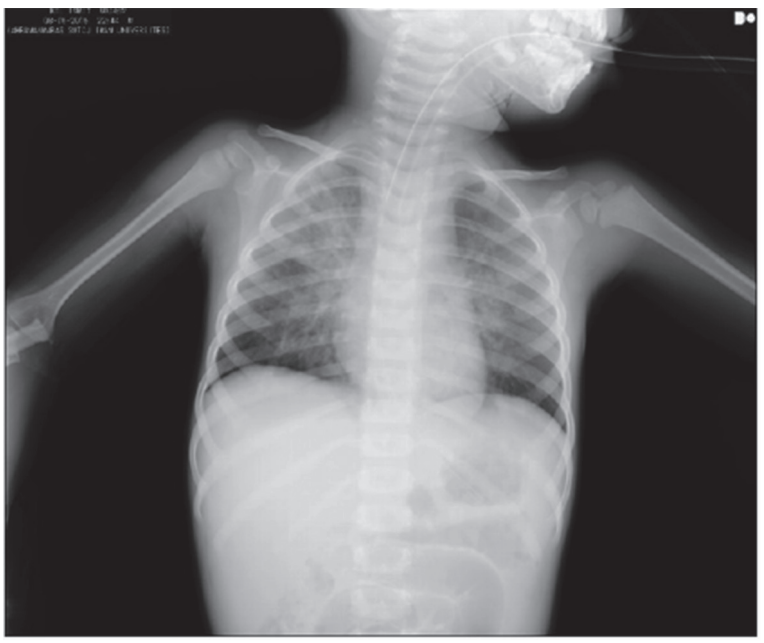

Figure 2. Posteroanterior chest $\mathrm{X}$-ray: The lung is better expanded and the edema has contracted. (Appearance $12 \mathrm{~h}$ after the neardrowning incident)

salt or fresh water leads to hypoxemia with the formation of alveolar-capillary oxygen difference. The degree of hypoxia depends on several factors, such as duration of submersion, water temperature, the patient's age, early initiation of advanced life support, and time to admission to the emergency department and intensive care. Previous studies have generally compared prognosis with water temperature and the duration of submersion. Many studies have reported that good outcomes are associated with the duration of submersion and the patient's age $(4,5)$. In one retrospective study, Quan et al. (4) examined 2628 cases of drowning and observed that better outcomes were obtained in drowning lasting up to 10 minutes, at a level of 34\% (95\% confidence interval 1.01-1.79), in children aged 0-4 years. The authors have emphasized that the outcomes may be poorer in subjects submerged for longer than 10 minutes, and that rescue and resuscitation efforts need to be revised. However, 
since durations of submersion depend on witness estimates, comparison with more rational values determining prognosis (such as $\mathrm{pH}$, lactate levels, neuron-specific enolase, plasma glucose levels, and cardiac troponin I) may elicit more reliable findings $(6,7)$.

Studies concerning water temperature have reported inconsistent findings. Tipton and Golden (8) reported that low water temperature was associated with better outcomes, while Quan et al. (4) determined no relation between water temperature and outcome. Our patient was found in water with a temperature above $4{ }^{\circ} \mathrm{C}$. Although the duration of immersion was uncertain, he had drowned in such a way as to rise to the surface of the water. Respiration was superficial when the patient was found, he was not intubated by the first aid team, and he was brought to the emergency department with respiration support via positive pressure mask. Hypoxemia findings, severe metabolic acidosis, bleeding diathesis, convulsion and loss of consciousness were observed on arrival at the emergency department. Pulmonary symptoms may assume various forms in cases of drowning and near-drowning. Patients may be entirely asymptomatic, or may exhibit clinical findings even including pulmonary edema and acute Respiratory Distress syndrome. Pulmonary edema in our case was determined clinically and radiologically (Figure 1). We applied fluid restriction, the amount of fluid to be given being adjusted on the basis of blood pressure, hourly urine output and central venous pressure, after which the patient was started on diuretic therapy. PEEP was applied at a level of $5 \mathrm{~cm} / \mathrm{H}_{2} \mathrm{O}$ in SIMV+PS mode with conventional mechanical ventilation. Optimal benefit was obtained from PEEP, and the patient was successfully removed from the mechanical ventilator after 48 hours. Ampicillin-sulbactam therapy was initiated due to the patient's being intubated, the fact that the manifestation of pulmonary edema could not be completely differentiated from pneumonia, and because the incident had taken place in a trough used for watering animals. No growth occurred in tracheobronchial aspirate cultures at follow-up, and pneumonia did not develop. This was in agreement with studies showing that drowning in polluted, fresh or salt water does not have an impact on the outcomes (9). Other systemic complications of near-drowning include hypothermia, metabolic acidosis, electrolyte imbalance, hemolytic anemia and hypo- and hypervolemia. Hypothermia is a commonly encountered condition in cases of drowning and near-drowning. It is particularly significant in terms of causing impairment of heart functions. However, rapid-onset hypothermia is also known to have a protective effect on the central nervous system (CNS). We think that hypothermia played a role in our patient's recovery without neurological sequelae. We also think that our patient's being very young, and therefore having good neuronal plasticity, also contributed to his protection against hypo-hyperglycemia, hypohypertension and hypo-hyperoxemia. The CNS indisputably undergoes the most significant damage in hypoxemia. Bradycardia, submersion exceeding 10 minutes in duration,
GCS being $<5$, blood glucose level $>300 \mathrm{mg} / \mathrm{dL}$ and a lactic acid level on the first day of $>6 \mathrm{mmol} / \mathrm{L}$ are regarded as poor prognostic indicators in cases resulting in death or severe neurological deficit (10). In conclusion, incidents of drowning or near-drowning represent an important cause of hypoxic brain damage frequently seen in the summer months. Since the duration of hypoxemia is an important factor in determining prognosis, basic life support training needs to be given to all individuals responsible for child care in order for them to be able to intervene promptly and appropriately. In addition, advanced life support courses need to be made more available in order to overcome gaps in knowledge and skills on the part of first aid teams performing initial procedures and of all emergency personnel. Care must be taken over fluid electrolyte and the acid-alkali balance through invasive arterial and venous monitoring in intensive care management, and metabolic acidosis must be corrected. PEEP is highly effective, in addition to protective mechanical ventilation strategies, in resolving pulmonary edema in those cases in which it develops.

\section{Ethics}

Informed Consent: Informed consent was obtained from the patient's parents.

Peer-review: Externally peer-reviewed.

Author Contributions: Concept: M.D., Y.Ç., Design: Y.Ç., M.D., Supervision: M.D.,

Data Collection or Processing: Y.Ç., Analysis or Interpretation: M.D.,Y.Ç., Literature Search: Y.Ç, M.D., Writing:Y.Ç, M.D., Critical Review: M.D.

Conflict of Interest: No conflict of interest was declared by the authors.

Financial Disclosure: The authors declared that this study has received no financial support.

\section{References}

1. Guidelines for cardiopulmonary resuscitation, international consensus on science. Part 8 Section 3: Advanced challenges in resuscitation, submersion or near drowning. Circulation 2000;102(Suppl 1):233-6.

2. Centers for Disease Control. Fatal injuries to children-United States, 1986. MMWR 1990;39:442-51.

3. Smith ML, Auer RN, Siesjo BK. The density and distribution of ischemic brain injury in the rat following 2-10 min of forebrain ischemia. Acta Neuropathol 1984;64:319-32.

4. Quan L, Mack CD, Schiff M. Association of water temperature and submersion duration and drowning outcome. Resuscitation 2014;85:790-4.

5. Suominen P, Baillie C, Korpela R, Rautanen S, Ranta S, Olkkola KT. Impact of age, submersion time and water temperature on outcome in near-drowning. Resuscitation 2002;52:247-54

6. Topjian AA, Berg RA, Bierens JJ, et al. Brain resuscitationin the drowning victim. Neurocrit Care 2012;17:441-6.

7. Graf WD, Cummings $P$, Quan L, Brutocao D. Predicting outcome in pediatric submersion victims. Ann Emerg Med 1995;26:312-9. 
8. Tipton MJ, Golden FS. A decision-making guide for the search, rescue and resuscitation of submersion (head under) victims based on expert opinion. Resuscitaion 2011;82:814-9.

9. Shephard E, Quan L. Drowning and submersion injury. In: Kliegman M, Stanton B, Schor N, Behrman RE, (eds).
Nelson textbook of pediatrics 19th ed. Philadelphia, WB Saunders Company, 2011:341-9.

10. Torres SF, Rodríguez $M$, lolster $T$, et al. Near drowning in a pediatric population: epidemiology and prognosis. Arch Argent Pediatr 2009;107:234-40. 